\title{
Assessment of Candida spp. frequency in the oral cavity ontocenosis of healthy individuals in different age groups
}

\author{
Jolanta Szymańska', Agnieszka Wójtowicz², Anna Malm² \\ ${ }^{1}$ Chair and Department of Paedodontics, Medical University of Lublin, Poland \\ ${ }^{2}$ Chair and Department of Pharmaceutical Microbiology with Laboratory for Microbiological Diagnostics, Medical \\ University of Lublin, Poland
}

Szymańska J, Wójtowicz A, Malm A. Assessment of Candida spp. frequency in the oral cavity ontocenosis of healthy individuals in different age groups. J Pre-Clin Clin Res. 2016; 10(2): 91-94. doi: 10.5604/18982395.1227563

\begin{abstract}
Introduction. Among the microorganisms colonizing the oral cavity ontocenosis, an important role is played by fungi: mainly yeast-like fungi of the Candida genus, and especially by the species C. albicans.

Objective. The aim of this study was to evaluate the frequency of oral colonization by Candida species in healthy individuals of different age groups, and to identify the species of the isolates.

Materials and method. The fungi were isolated from the oral cavities of 654 healthy individuals of both genders, representing different age groups, and the species of the isolates were determined. Initial identification of the yeast-like fungi was made based on the macroscopic appearance of the colonies on Sabouraud's medium, and the growth of coloured colonies on ChromAgar Candida medium. API 20 C AUX microtest (bioMerieux) was used to identify the most frequently found species of Candida spp.

Results. The frequency of Candida isolation from the oral cavity ontocenosis in healthy individuals of different age groups was assessed as $30.6 \%$. The oral cavity ontocenosis was colonized mainly by the yeast-like fungi of C. albicans species: they were found in $24.5 \%$ of the tested population, while the frequency of oral cavity colonization by non-albicans Candida spp. was $6.1 \%$. Seven species of non-albicans Candida spp. were identified: C. glabrata, C. inconspicua, C. famata, C. tropicalis, C. parapsilosis, C. lusitaniae, and C. kefyr.

Conclusions. In the Polish population, $30.6 \%$ of the oral cavity ontocenosis is colonized by Candida yeast-like fungi, while C. albicans is the fungus that colonizes oral cavity ontocenosis most frequently. The frequency of oral cavity ontocenosis colonization with Candida spp (including C. albicans) increases with age.
\end{abstract}

\section{Key words}

fungi, Candida spp, Candida albicans

\section{INTRODUCTION}

The oral cavity is a specific ecosystem populated with numerous aggregations of various microbial species. Fungi, mainly yeast-like fungi of Candida genus, including especially Candida albicans, have an important place among microorganisms colonizing the oral cavity ontocenosis $[1,2$, 3]. Yeast-like fungi are microorganisms very well adapted to overcome the defence mechanisms of the human organism. Among various $C$. albicans virulence factors, the most important role is attributed to its biofilm-forming abilities $[4,5,6]$.

The aim of this study was to evaluate the frequency of oral colonization by Candida species in healthy individuals of different age groups, and to identify the species of the isolates.

\section{MATERIALS AND METHOD}

The study material included Candida yeast-like fungi strains isolated from the oral cavity ontocenosis of healthy individuals in different age groups. Swab samples from the oral cavity were taken from 654 individuals of both genders,

Address for correspondence: Jolanta Szymańska, Chair and Department of Paedodontics, Medical University of Lublin, Poland

E-mail: szymanska.lublin@gmail.com

Received: 11 December 2016; accepted: 16 December 2016 residents of south-eastern Poland (Central-Eastern Europe). The study did not include patients undergoing orthodontic treatment with fixed and removable appliances, nor those using fixed or removable dental prostheses.

It was shown that such appliances affect the microbiological environment and cause an increase in the prevalence of Candida in the mouth $[7,8]$. The examined persons were divided into groups according to age (Tab. 1). Immediately after sampling, or after sampling and placing on transport medium, the study material (swab samples from the oral cavity) was inoculated into Sabouraud's medium with chloramphenicol and into ChromAgar Candida. The inoculates were incubated

Table 1. Studied populations

\begin{tabular}{lcc}
\hline Studied group & $\begin{array}{c}\text { Age brackets } \\
\text { (years) }\end{array}$ & $\begin{array}{c}\text { Number } \\
\text { of persons }\end{array}$ \\
\hline 0 (neonates, infants, children attending day nurseries) & $0-3$ & 102 \\
\hline 1 (children attending kindergartens) & $4-6$ & 82 \\
\hline 2 (primary school children) & $7-14$ & 91 \\
\hline 3 (secondary school adolescents) & $15-18$ & 101 \\
\hline 4 (students) & $19-25$ & 92 \\
\hline 5 (professionally-active individuals) & $26-45$ & 79 \\
\hline 6 (professionally-active individuals, pensioners, old- & $46-65$ & 53 \\
\hline age pensioners) & & 54 \\
\hline 7 (wards of social welfare homes) & $\geq 66$ & 5 \\
\hline
\end{tabular}


for $48 \mathrm{~h}$ at $35^{\circ} \mathrm{C}$. The initial identification of yeast-like fungi was based on the macroscopic appearance of the colonies on Sabouraud's medium, and of the growth of coloured colonies on ChromAgar Candida medium. Further tests were performed on the isolates that formed cream-coloured, smooth or slightly wavy, concave, glossy, smelling of yeast, and creamy-textured colonies. Yeast-like fungi were isolated on Sabouraud's medium. The inoculates were incubated for $48-72 \mathrm{~h}$ at $35^{\circ} \mathrm{C}$. In the microscopic preparations stained with Gram's method, Gram-positive thin-walled, spherical, cylindrical or egg-shaped 4-6 $\mu \mathrm{m}$ balstospores were found. The identification of the most common species of Candida spp. was performed with API 20 C AUX test (bioMerieux).

\section{RESULTS}

According to the data presented in Table 2, the frequency of isolating Candida yeast-like fungi from the oral cavity ontocenosis of the study population of healthy individuals in different age groups was $30.6 \%$; in all age groups, this index varied from $22.5 \%$ in the youngest group (Group 0 ) to $52.0 \%$ in the oldest group (Group 7). Group 6, composed of 3 mature people, was characterized with a high level of oral cavity colonization, reaching $45.3 \%$. The results for the remaining age groups were similar, from $25.7 \%-30.4 \%$.

Table 2. Frequency of Candida spp., including C. albicans, in the oral cavity ontocenosis of healthy individuals in different age groups

\begin{tabular}{cccccc}
\hline $\begin{array}{c}\text { Studied } \\
\text { group }\end{array}$ & $\begin{array}{c}\text { Number } \\
\text { of } \\
\text { persons }\end{array}$ & $\begin{array}{c}\text { Age } \\
\text { bracket }\end{array}$ & $\begin{array}{c}\text { Number } \\
\text { (percentage) } \\
\text { of persons } \\
\text { colonized by } \\
\text { Candida spp. }\end{array}$ & $\begin{array}{c}\text { Number } \\
\text { (percentage) } \\
\text { of persons } \\
\text { colonized by } \\
\text { C. albicans }\end{array}$ & $\begin{array}{c}\text { Number } \\
\text { (percentage) } \\
\text { of persons } \\
\text { colonized by } \\
\text { non-albicans } \\
\text { Candida spp. }\end{array}$ \\
\hline 0 & 102 & $0-3$ & $23(22.5)$ & $17(16.7)$ & $6(5.8)$ \\
\hline 1 & 82 & $4-6$ & $25(30.4)$ & $20(24.4)$ & $5(6.0)$ \\
\hline 2 & 91 & $7-14$ & $24(26.4)$ & $21(23.0)$ & $3(3.3)$ \\
\hline 3 & 101 & $15-18$ & $26(25.7)$ & $21(20.8)$ & $5(5.0)$ \\
\hline 4 & 92 & $19-25$ & $26(28.3)$ & $22(24.0)$ & $4(4.3)$ \\
\hline 5 & 79 & $26-45$ & $24(30.4)$ & $20(25.3)$ & $4(5.0)$ \\
\hline 6 & 53 & $46-65$ & $24(45.3)$ & $19(35.8)$ & $5(9.5)$ \\
\hline 7 & 54 & $\geq 66$ & $28(52.0)$ & $20(37.0)$ & $8(14.8)$ \\
\hline Total & 654 & - & $200(30.6)$ & $160(24.5)$ & $40(6.1)$ \\
\hline
\end{tabular}

The oral cavity ontocenosis in the study population was colonized mainly by C. albicans yeast-like fungi; they were found in $160(24.5 \%)$ persons. The level of C. albicans in all the studied groups varied from $16.7 \%$ in Group 0 to $37.0 \%$ in Group 7. A high colonization level was found also in Group 6, reaching $35.8 \%$. In the remaining age groups, the results were similar and varied from $20.8 \%-25.3 \%$.

The frequency of oral cavity colonization with nonalbicans Candida spp. yeast-like fungi in the study population was $6.1 \%$; their presence was found in $40(20 \%)$ persons. In different age groups, the frequency of those yeast-like fungi varied from 3.3\% (Group 2) to $14.8 \%$ (Group 7). A high level of colonization with those yeast-like fungi was also found in Group 6 (9.5\%). The frequency of isolating non-albicans Candida spp. in the remaining age groups was similar and varied from $4.3 \%-6 \%$.
The frequency of different species of Candida spp. in the oral cavity in the studied population of healthy individuals from various age groups is presented in Figure 1. The percentage share of C. albicans in the isolated yeast-like fungi varied from $71.4 \%$ (Group 7) to $87.4 \%$ (Group 2). In total, 7 species of non-albicans Candida spp. were identified: C. glabrata, C. inconspicua, C. famata, C. tropicalis, C. parapsilosis, C. lusitaniae, and C. kefyr; the species composition of those yeast-like fungi differed in various age groups. The percentage share of non-albicans Candida spp. varied from $12.6 \%$ (Group 2) to 26\% (Group 0). In individual groups, from 3-5 species were isolated. The simultaneous presence of two species of Candida genus was found in 16 (8\%) persons.

\section{DISCUSSION}

According to literature data [1, 3, 9-22], Candida yeast-like fungi can occur in healthy people with frequency from $10 \%$ $100 \%$. The results obtained in this study, both concerning the frequency of Candida spp. (30.6\%) and of C. albicans (24.5\%), in the examined population fall into the range indicated by other authors $[1,3,22]$.

It seems important that these indices differ according to age group. In the presented study, the carriership of Candida spp. and C. albicans in all studied groups varied from $22.5 \%$ in the youngest age group to $52.0 \%$ in the oldest age group, and from $16.7 \%-37.0 \%$, respectively. These data confirm that with age there is an increasing tendency in the level of oral cavity ontocenosis colonization with Candida spp. (including C. albicans), while in children, youths and professionally-active individuals, a certain plateau can be observed. According to the authors, old age has been shown as one of the factors related to Candida carriage. This is related to salivary glands hypofunction, reduced salivary flow rate, intensification of periodontal diseases with age, a decrease in manual dexterity connected with age, poor oral hygiene habits in the elderly, and metabolic diseases causing serious multiorgan disturbances (e.g. diabetes mellitus or decreasing immunity) [23].

As the literature data shows $[1,3,22]$, C. albicans continues to be a prevailing yeast-like fungi species that can be found in the oral cavity. This is confirmed by the results obtained in the present study. It was shown that $80 \%$ of all the isolated strains of Candida spp. belonged to that species. It should be noted, however, that a tendency to shift the balance towards non-albicans Candida spp. species occurs especially in patients with immunity disorders $[1,11,12,13,14,15]$. In the presented study, this tendency could be observed in the oldest age groups, where the indices of non-albicans Candida spp. species isolation were significantly higher (14.8\%) than in younger age groups (3.3\%).

\section{CONCLUSIONS}

1. In the Polish population, $30.6 \%$ of the oral cavity ontocenosis is colonized by Candida yeast-like fungi.

2. C. albicans is a yeast-like fungus most frequently colonizing the oral cavity ontocenosis.

3. The frequency of oral cavity ontocenosis colonization with Candida spp. (including C. albicans) increases with age. 

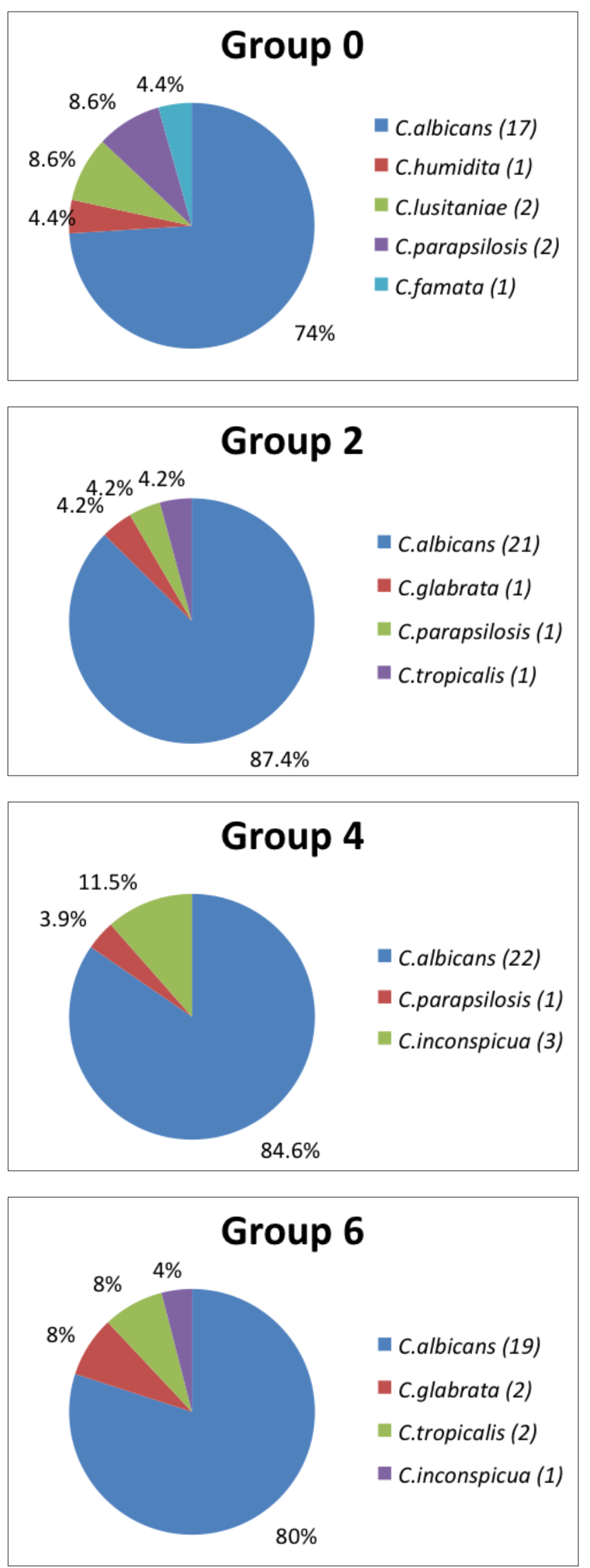

The number of isolates is given in parentheses.

Figure 1. Genetic grouping of Candida spp. isolated from oral cavity ontocenosis of healthy people of different age groups
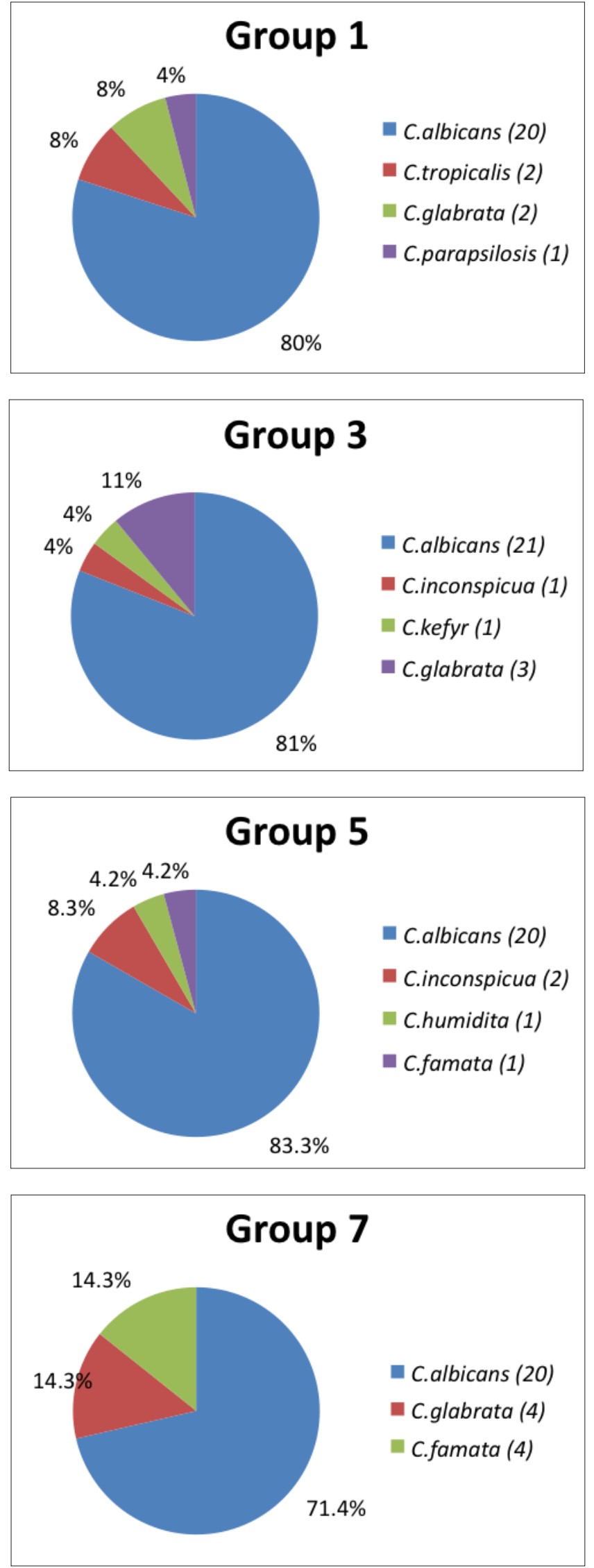


\section{REFERENCES}

1. Grimoud AM, Marty N, Bocquet H, et al. Colonization of the oral cavity by Candida species: risk factors in long-term geriatric care. J Oral Sci. 2003; 45(1): 51-55.

2. Kurnatowska AJ. Occurence of fungi in oral cavity ontocenosis and changes to the mucosa. Mikol Lek. 2003; 10(4): 295-298 (in Polish).

3. Siqueira J, Sen B. Fungi in endodontic infections. Oral Surg Oral Med Oral Pathol Oral Radiol Endod. 2004; 97: 632-641.

4. Karkowska-Kuleta J, Rapala-Kozik M, Kozik A. Fungi pathogenic to humans: molecular bases of virulence of Candida albicans, Cryptococcus neoformans and Aspergillus fumigatus. Acta Biochem Pol. 2009; 56 (2): 211-224.

5. Ramage G, Martinez JP, Lopez-Ribot JL. Candida biofilms on implanted biomaterials: a clinically significant problem. Yeast Res. 2006; 6: 979 986.

6. Thein ZM, Seneviratne CJ, Samaranayake YH, et al. Community lifestyle of Candida in mixed biofilms: a mini review. Mycoses 2009; 52(6): 467-475

7. Kyoko H, Wong RW, Hägg U, et al. The effect of orthodontic appliance on Candida in the human mouth. Int J Paediatr Dent. 2009; 19(5): 301-308.

8. Prakash B, Shekar M, Maiti B, et al. Prevalence of Candida spp. among healthy and nondenture wearers with respect to hygiene and age. J Indian Prosthodont Soc. 2015; 15(1): 29-32.

9. Back-Brito GN, Mota AJ, Vasconcellos TC, et al. Frequency of Candida spp. in the oral cavity of Brazilian HIV-positive patients and correlation with CD4 cell counts and viral load. Mycopatholgia 2009; 167: 81-87.

10. Barros LM, Boriollo MFG, Alves ACBA, et al. Genetic diversity and exoenzyme activities of Candida albicans and Candida dubliniensis from the oral cavity of Brazilian periodontal patients. Arch Oral Biol. 2008; 53: 1172-1178.

11. Biedunkiewicz A. Yeast-like fungi isolated in students. Acta Mycol. 2007; 42(1): 141-149 (in Polish).
12. Ejdys E. Factors predisposing appearance of yeasts-like fungi in healthy school age girls and boys. Mikol Lek. 2008; 15(2): 84-88 (in Polish).

13. Furlaneto-Maia L, Specian AF, Bizerra C, et al. In vitro evaluation of putative virulence attributes of oral isolates of Candida spp. obtained from elderly healthy individuals. Mycopathologia 2008; 166(4): 209-217.

14. Hu T, Qi QG, Zhou XD. Frequency, species and molecular characterization of oral Candida in host of different age in China. J Oral Pathol Med. 2005; 34: 352-356.

15. Qi QG, Wang WX, Zhou XD, et al. The distribution of Candida spp. in the oral cavities of normal children. Shanghai Kou Qiang Yi Xue 2003; 12(4): 288-291.

16. Qi QG, Hu T, Zhou XD. Frequency, species and molecular characterization of oral Candida in host of different age in China. J Oral Pathol Med. 2005; 34: 352-356.

17. Resende M, Franco de Sousa LVN, Oliveira RCBW, et al. Prevalence and antifungal susceptibility of east obtained from the oral cavity of elderly individuals. Mycopathol. 2006; 162: 39-44.

18. Rożkiewicz D, Daniluk T, Zaremba ML, et al. Oral Candida albicans carriage in healthy preschool and school children. Adv Med Scn. 2006; 51(1): 187-190.

19. Ślebioda Z, Hemerling M, Błauciak M, et al. Occurence of yeast-like fungi of the Candida spp. in high school youth, healthy adults without systemic diseases. Dent Forum 2007; 35(1): 23-26 (in Polish).

20. Vale-Silva L, Goncalves M, Cavaleiro C, et al. Antifungal activity of the essential oil of Thymus $\mathrm{x}$ viciosoi against Candida, Cryptococcus, Aspergillus and dermatophyte species. Planta Med. 2010; 76(9): 882-888.

21.Zaremba ML, Daniluk T, Rożkiewicz D, et al. Incidence rate of Candida species in the oral cavity of middle-aged and elderly subjects. Adv Med Sci. 2006; 51(1): 233-236.

22. Żurowski M, Szponar-Żurowska A, Jarzębowska M, et al. Occurence of yeast-like fungi of the Candida spp. in high school youth. Czas Stomatol. 1994; 47(4): 259-262 (in Polish).

23. Sardi JC, Almeida AM, Mendes Giannini MJ. New antimicrobial therapies used against fungi present in subgingival sites - a brief review. Arch Oral Biol. 2011; 56(10): 951-959. 